\title{
OUTCOME OF CONTINUOUS LOW DOSE ANTIBIOTIC TREATMENT IN COMPARISON WITH PERI- INTERVENTION ANTIBIOTIC PROPHYLAXSIS IN DOUBLE J STENTING
}

\author{
MARUF AHMED ${ }^{1}$, MD. NAZRUL ISLAM ${ }^{2}$, AMIRUL ISLAM ${ }^{3}$, MD. JAHANGIR ALAM ${ }^{4}$, MD. MOSTAFIZUR \\ RAHMAN $^{5}$, MD. NABID ALAM 6
}

\begin{abstract}
Objective: To determine the outcome of antibiotic treatment regime in patient with indwelling DJ stenting having a per-interventional antibiotic prophylaxis compared with those of a continuous low-dose antibiotic treatment.

Methods: A hospital based prospective experimental study was conducted in the Department of Urology of Dhaka Medical College Hospital, Dhaka from July 2012 to June 2014, to evaluate the antibiotic treatment regime in patient with indwelling DJ stenting, the benefits and disadvantages of a peri-interventional antibiotic prophylaxis compared with those of a continuous low-dose antibiotic treatment by enrolling a total number of 60 subjects in the department of Urology, Dhaka Medical College, Dhaka. Among 60 subjects 30 subjects were Group A comprised of subjects treated with continuous low dose antibiotic and Group $B$ with 30 subjects treated with peri-interventional antibiotic. The patients would undergo temporary $D \mathrm{~J}$ stent placement due to upper tract urolilhiasis who meet the inclusion criteria and exclusion criteria. Informed written consent would be taken from all patients. Urine samples would be analysed conventional antibiotic susceptibility and resistance was determined. All analyses was conducted at department of Microbiology, Dhaka medical college hospital. All patients who received peri-interventional antibiotic prophylaxis with $1 \mathrm{~g}$ ceftriaxon was given I.v. at anaesthesia induction to obtain a peak concentration at the time of highest risk during the procedure.According to the pathogens profile and susceptibility, the antimicrobial agent of choice for continuous low-dose treatment was Cefixim 200mg twice daily. All stents placements were performed under sterile conditions applying a retrograde technique or antregrade in PCNL and open procedure under spinal or general anaesthesia. Patients were prescribed ketorolac (10mg) or Tramadol (50mg), while none of the patient received alpha blocker agents or anti-cholinergic drugs. Evaluations for UTI were performed before stent insertion and consecutively after 1, 2 and 4 weeks and/or at stent withdrawal.
\end{abstract}

Statistical analysis of the result was obtained by using window based computer software devised with statistical packages for social science (SPSS-20 IBM) (SPSS inc, Chicago, IL, USA). The result was presented in tables, figures, and diagrams. Statistical test was done by Chi square test and $Z$ test for qualitative data and $t$ test for quantitative data. $A$ $p$-value $<0.05$ is considered as level of significance.

Results: To evaluate the antibiotic treatment regime in patient with indwelling $D J$ stenting, the benefits and disadvantages of a peri-interventional antibiotic prophylaxis compared with those of a continuous low-dose antibiotic treatment, a total number of 60 subjects

1. Assistant Professor Urology, Sher-E-Bangla Medical College, Barisal.

2. Assistant Professor Urology, Sher-E-Bangla Medical College, Barisal.

3. Assistant Professor Urology, Sheikh Sayera Khatun Medical College.Gopalgong

4. Associate Professor Urology, Sheikh SayeraKhatun Medical College.Gopalgong.

5. Assistant Professor Urology, Khaja Yunus Ali Medical College.Enayetpur, Sirajgonj.

6. MS Urology, Resident DMCH, Dhaka., Medical officer urology dept, BSMMU.

Correspondence: Dr. Maruf Ahmed MBBS, MS (Urology). Assistant Professor Urology, Sher-E-Bangla Medical College, Barisal. Phone:+8801711472130, dr.marufuro1973@gmail.com

Received: 9 August $2017 \quad$ Accepted: 05 March 2018 
were enrolled in this present study in the department of Urology, Dhaka Medical College, Dhaka. Among 60 subjects 30 subjects were Group A comprised of subjects treated with continuous low dose antibiotic and Group $B$ with 30 subjects treated with periinterventional antibiotic only. Outcome of these two treatment techniques were studied.

For urinary tract infection rate the concept of a peri-interventional antibiotic prophylaxis during $D J$ stent implantation is known to be better antibiotic coverage and is therefore recommended by the European Association of Urology. However, there is a lack of evidence concerning the exact antibiotic strategy for the entire stent-indwelling time. In clinical routine, it is an applied practice among urologists to continue antibiotic treatment in a low-dose fashion, even after previous uncomplicated implantations.

Conclusion: In case of indwelling DJ stenting, subjects with continuous low dose antibiotic regimen had significantly less proportion of UTI, dysuria and frequency of micturition than those with peri-interventional antibiotic. So, if haematuria, skin rash and GIT disturbance is carefully managed then continuous low dose antibiotic regimen is better treatment option than peri-interventional regimen for with indwelling $D J$ stenting in different cases.

Bangladesh J. Urol. 2018; 21(2): 127-136

\section{Introduction:}

Urinary tract infections (UTIs) are among the most prevalent infectious diseases with a substantial financial burden on society. Unfortunately, there are also no good data concerning the prevalence of various types of UTIs and their impact on the quality of life of the affected population. For a well-functioning public health system, such data are urgently needed. Data obtained from other countries and societies, e.g. the USA, can only be applied with caution to the European situation. In the USA, UTIs are responsible for over 7 million visited annually, including more than 2 million visits for cystitis[1,13]. Approximately $15 \%$ of all community-prescribed antibiotics in the USA are dispensed for UTI. Urinary tract infections account for more than 100,000 hospital admissions annually, most often for pyelonephritis. They also account for at least $40 \%$ of all hospital-acquired infections and are in the majority of cases catheterassociated[10]. Ureteral stents represent the most mature application of an indwelling end luminal splint, having first been described in 1967. As originally described, the intent of implantation was for the treatment of ureteral obstruction or fistula. As a result, the indications for ureteral stent placement have expanded significantly. Ureteral stent placement is now considered a standard and indispensable urologic tool. As the technique has evolved, so has the design of the implanted device. It should be recognized, however, that no currently available device fulfills all of the criteria for the "ideal" stent. Certain consequences can be anticipated with implantation of a foreign object into the urinary tract. There can also be unexpected complications. Radiology plays an important role in the requisite monitoring of patients with indwelling stents as well as in evaluation of and potential therapy for the consequences and complications associated with stents. In this article, the evolution of stent designs was reviewed and complications, including urinary tract infection, malposition and migration, inadequate relief of obstruction, encrustation, stent fracture, ureteral erosion or fistulization, and the forgotten stent were studied[2.3]. For urinary tract infection rates the conception of a periinterventional antibiotic prophylaxsis during endoscopic DJ stent implantation is known to be better than no antibiotic coverage and is therefore recommended by the European Association of Urology[5]. However, there was a lack of evidence concering the exact antibiotic strategy for the entire stent-indwelling time. In clinical routine, it is an applied practice among urologist to continue antibiotic treatment in a low -dose fashion, even after previous uncomplicated implantations. The intention is to lower the rates of UTIs and to achieve a positive effect on stent-related symptoms. There exists neither evidence for the benefit, nor for the potential disadvantages of such empirical prevention. Moreover, increasing rates of bacterial drug resistances, growing overall healthcare costs and drug side-effects require a critical antibiotic prescription policy[6,4].

\section{Materials and methods:}

This Hospital based Quasi experimental study done in Department of Urology, Dhaka Medical College and Hospital. at the Period of July 2012 to June 2014.. In this prospective study sixty consecutive patients were selected as per selection criteria from the patients attending in the out patient department as well as in patient department of urology unit, Dhaka Medical College Hospital, Dhaka with the complaints with upper tract urolithiasis were enrolled in the study and were convinced to participate in the study after giving written 
consent and satisfying inclusion and exclusion criteria. A total sixty patients with DJ stent in situ were included in our study.

Inclusion criteria were asge about $18-70$ years, All admitted patients who received peri-interventional antibiotic prophylaxsis and double $\mathrm{J}$ stenting for urelithiasis. Sterile urinary culture before stent placement, afebrile patient. Patients who gave no antibiotic before operation for last two weeks.

Exclusion Criteria were age below 18years. Positive urine culture. Septicaemia requiring full-dose antibiotic treatment. Severe co-morbidities. Bleeding disorders. Pregnancy.Patients with abnormal bladder function and urinary diversion

Sampling technique: Purposive sampling was done. Diagnosed patient of upper tract urolithiasis and study place were selected first purposively who met the inclusion criteria selected for the study. Details of patients' relevant history, chief and present complaints and physical examination findings were recorded. Patients were evaluated carefully and the particulars of the patients, including history and clinical examination were taken in the prescribed form note.

Variable studied: Demographic variable-Age of patient, Sex, Body mass index.

Outcome variables: UTI, Dysuria, Haematuria, Frequency day and night time separately, Pain(flank/ suprapubic), General health(including possible drug side effects, e.g. gastro-intestinal symptoms and rash).

Statistical analysis of the result was obtained by using window based computer software devised with statistical packages for social science (SPSS-20 IBM) (SPSS inc, Chicago, IL, USA). The result was presented in tables, figures, and diagrams. Statistical test was done by Chi square test and $Z$ test for qualitative data and $t$ test for quantitative data. A p-value $<0.05$ is considered as level of significance.

\section{Study design:}

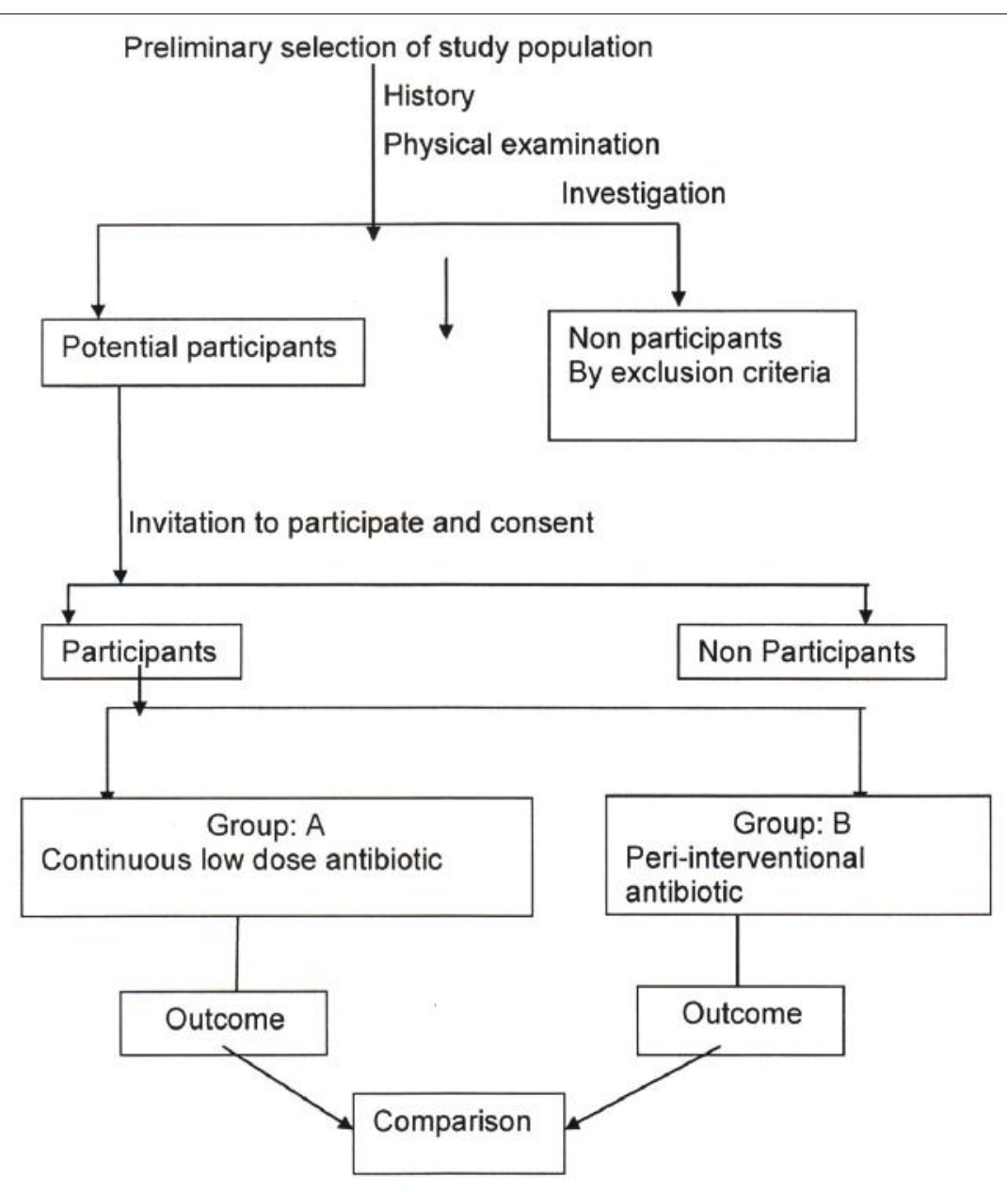

Flow chart of study design 
Results:

To evaluate the antibiotic treatment regime in patient with indwelling DJ stenting, the benefits and disadvantages of a peri-interventional antibiotic prophylaxis compared with those of a continuous lowdose antibiotic treatment, a total number of 60 subjects were enrolled in this present study in the department of Urology, Dhaka Medical College, Dhaka. Among 60 subjects 30 subjects were Group A comprised of subjects treated with continuous low dose antibiotic and Group B with 30 subjects treated with peri-interventional antibiotic only. Outcome of these two treatment techniques were studied.
Table-I

Is showing the patient characteristics

\begin{tabular}{lc}
\hline Variable & Value $(\%)$ \\
\hline Mean \pm SD age (years) & $43.37(08.83)$ \\
Sex, $n$ & \\
Male & $38(63.33)$ \\
Female & $22(36.67)$ \\
Side, $n$ & \\
Right & $32(53.34)$ \\
Left & $28(46.66)$ \\
Mean \pm SD BMI, $\mathrm{kg} / \mathrm{m}^{2}$ & $22.98(03.83)$ \\
\hline
\end{tabular}

$\mathrm{n}=$ number

In group A 20 (66.66\%) were male and rest 10 (33.34\%) were female. In group B 18 (60\%) were male and $12(40 \%)$ were female. No significant gender difference was seen between these two groups (revealed by Chi square test

Table II

Age distribution of the study subjects

\begin{tabular}{lcccc}
\hline Age (in year) & $\begin{array}{c}\text { Group A } \\
\mathrm{n}=30\end{array}$ & \multicolumn{2}{c}{$\begin{array}{c}\text { Group B } \\
\mathrm{n}=30\end{array}$} \\
& Number of subjects & Percentage & Number ofsubjects & Percentage \\
\hline $1.30-40$ & 10 & 30.00 & 12 & 40.0 \\
$2.41-50$ & 15 & 50.00 & 14 & 46.66 \\
$3.51-60$ & 05 & 20.00 & 04 & 13.33 \\
Mean \pm SD & $42.64(09.63)$ & \multicolumn{2}{c}{ 23.17(08.12) } \\
\hline \multicolumn{2}{l}{ Statistical test(table value/ P-value) } & \multicolumn{2}{c}{$2.59 / 0.746$} \\
\hline
\end{tabular}

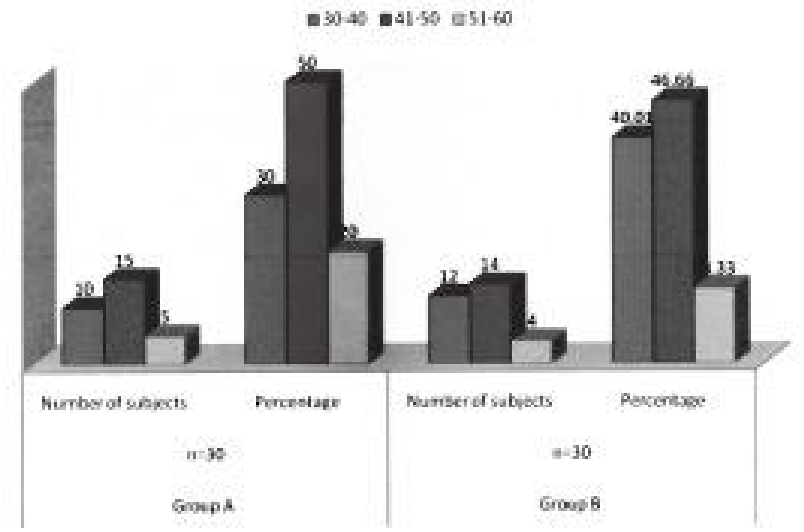

Fig.-1: Bar diagram showing age distribution of the study subjects

\section{Difference between ages in two groups was achieved by t-test.(paired)}

The study subjects were divided into three age groups. The age ranged from 31-60 years and the maximum number was found in 41 to 50 years age group. No significant age difference was seen between these two groups

In group A 20 (66.66\%) were male and rest 10 (33.34\%) were female. In group B 18 (60\%) were male and 12 $(40 \%)$ were female. No significant gender difference was seen between these two groups (revealed by Chi square test). 

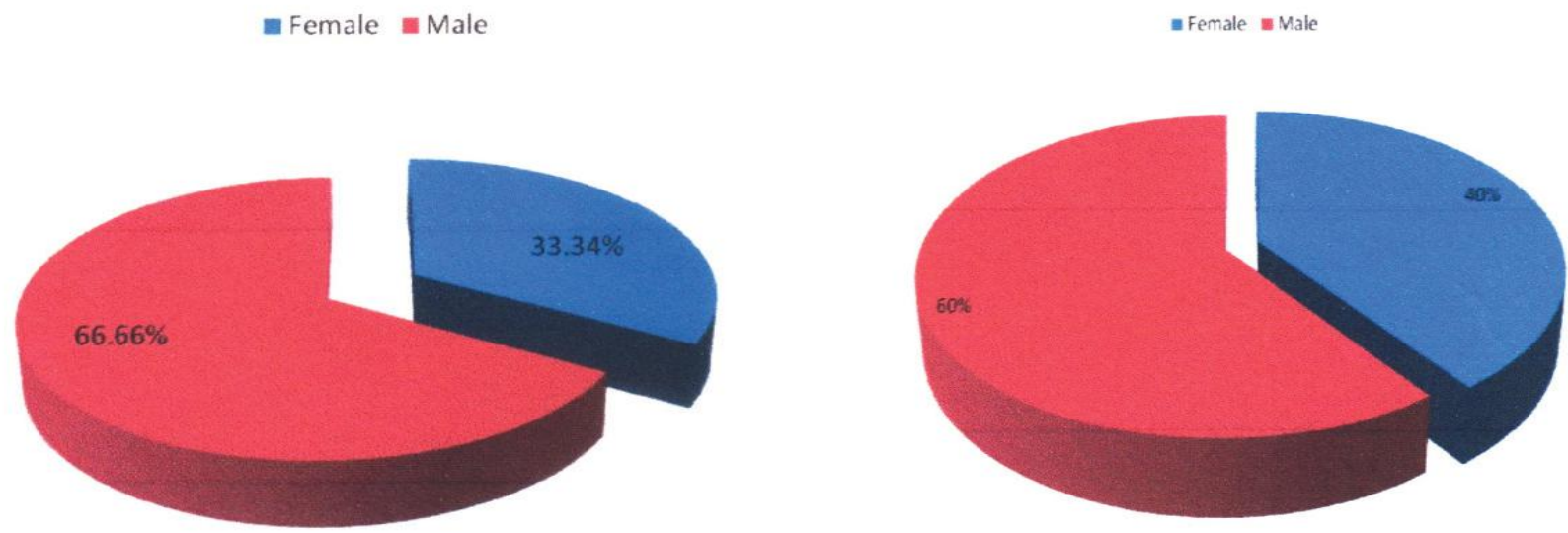

Figure 2: Pie diagram showing gender distribution of the study subjects

Table III

Mean BMI of the study subjects

\begin{tabular}{lcc}
\hline Group An=30 & Group B $\mathrm{n}=30$ & Statistical test \\
\hline BMI in $\mathrm{kg} / \mathrm{m}^{2} 23.74(03.52)$ & $23.11(03.96)$ & $0.549^{* \mathrm{NS}}$ \\
\hline
\end{tabular}

$*$ * test

NS= Non significant

It was seen that, mean BMI was $23.74( \pm 3.52) \mathrm{kg} / \mathrm{m}^{2}$ in group A and $23.11( \pm 3.96) \mathrm{kg} / \mathrm{m}^{2}$ in group B. No significant difference was seen between two groups.

Table IV

Univariate analysis of factors predicting success of continuous low dose antibiotic and peri-interventional low dose antibiotic

\begin{tabular}{lccc}
\hline Variable & $\begin{array}{c}\text { Continuous low } \\
\text { dose antibiotic }\end{array}$ & $\begin{array}{c}\text { Univariate } \\
\text { Peri-interventional } \\
\text { low dose antibiotic }\end{array}$ & $\mathrm{P}$ \\
\hline $\begin{array}{l}\text { Mean } \pm \text { SD age (years) } \\
\text { Sex, } n\end{array}$ & $42.64(09.63)$ & $43.17(08.12)$ & $0.746^{*}$ \\
Male & 20 & 18 & $0.221^{*}$ \\
Female & 10 & 12 & \\
Side, $n$ & & & $0.392 \#$ \\
Right & 18 & 14 & \\
Left & 13 & 15 & \\
Mean \pm SD) & & & $0.549^{* N S} 0.031^{\mathrm{s}}$ \\
BMI, kg/m ${ }^{2}$ UTI & $23.74(03.52) 03(10.00 \%)$ & $23.11(03.96) 08(26.67 \%)$ & $0.001^{\mathrm{s}}$ \\
Dysuria & $03(10.00 \%)$ & $11(36.67 \%)$ & $0.142^{\mathrm{NS}}$ \\
Haematuria & $03(10.00 \%)$ & $05(16.67 \%)$ & $0.001^{\mathrm{s}}$ \\
Increased frequency & $02(06.67 \%)$ & $07(23.33 \%)$ & $0.328^{\mathrm{NS}}$ \\
GIT disturbance & $05(16.67 \%)$ & $06(20.00 \%)$ & $0.001^{\mathrm{s}}$ \\
Skin Rash & $07(23.33 \%)$ & $02(06.67 \%)$ & \\
\hline
\end{tabular}

$*$ * test

\#=Chi-square test

$\mathrm{S}=$ Significant NS= Non significant, $\mathrm{N}=$ Number 
Tablel V

UTI among the study subjects

\begin{tabular}{lccc}
\hline Outcome & $\begin{array}{c}\text { Group A } \\
n=30\end{array}$ & $\begin{array}{c}\text { Group B } \\
n=30\end{array}$ & Statistical test \\
\hline UTI & $03(10.00 \%)$ & $08(26.67 \%)$ & $0.03 \mathrm{~V}$ \\
\hline
\end{tabular}

Statistical test was performed by $Z$ test. $S=$ Significant

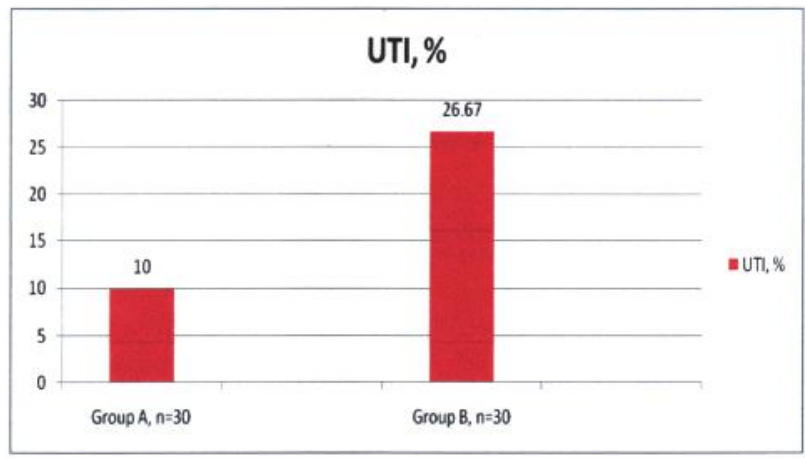

Fig.-3: Bar diagram showing percentage of UTI among the study

Proportion of UTI was statistically more (26.67\%) among those subjects receiving peri-interventional antibiotic than continuous low dose antibiotic supplementary $(10 \%)$.

Table VI

Dysuria among the study subjects-

\begin{tabular}{lccc}
\hline Outcome & Group A n=30 & Group B n=30 & Statistical test \\
\hline Dysuria & $03(10.00 \%)$ & $11(36.67 \%)$ & $0.001^{\mathrm{s}}$ \\
\hline
\end{tabular}

\section{Statistical test was performed by $Z$ test.}

$S=$ Significant

Dysuria was statistically less (10\%) among subjects receiving continuous low dose antibiotic supplementary than those with peri-interventional antibiotic (36.67\%).

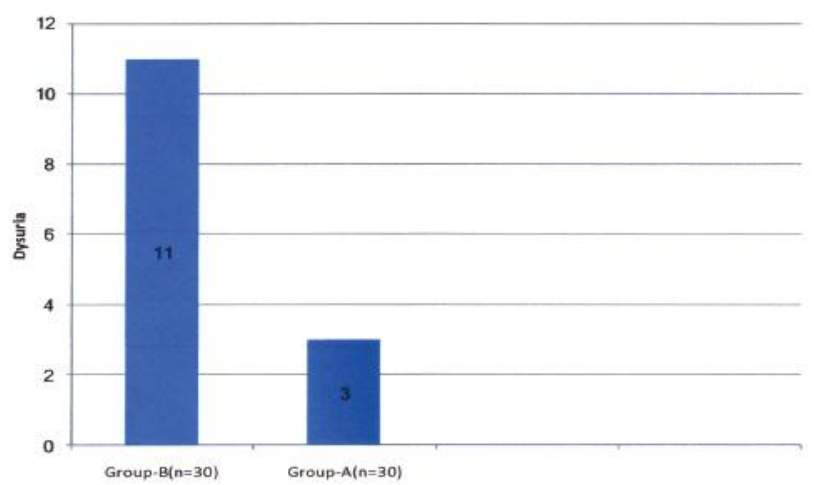

Fig.-4: Bar diagram showing Dysuria among the study subjects
Table VII

Haematuria among the study subjects

\begin{tabular}{lccc}
\hline Outcome Group A n=30 & Group B n=30 & Statistical test \\
\hline Haematuria $03(10.00 \%)$ & $05(16.67 \%)$ & $0.142^{\mathrm{NB}}$ \\
\hline
\end{tabular}

\section{Statistical test was performed by $Z$ test. NS=Not Significant}

Proportion of Haematuria was less $(10 \%)$ in subjects receiving continuous low dose antibiotic supplementary than those with peri-interventional antibiotic (16.67\%).

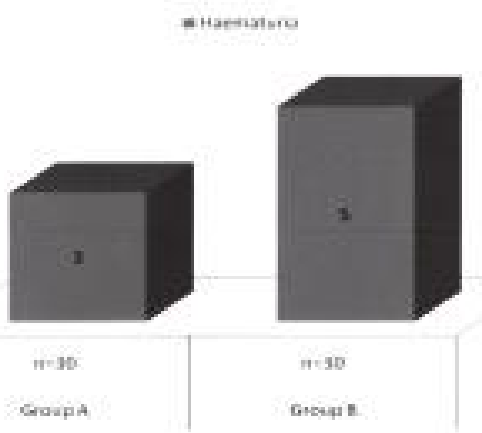

Fig.-5: Bar diagram showing Haematuria among the study subjects

Table VIII

Increased frequency among the study subjects-

\begin{tabular}{lccc}
\hline Outcome & $\begin{array}{c}\text { Group A } \\
\mathrm{n}=30\end{array}$ & $\begin{array}{c}\text { Group B } \\
\mathrm{n}=30\end{array}$ & $\begin{array}{c}\text { Statistical } \\
\text { test }\end{array}$ \\
\hline Increased & $02(06.67 \%)$ & $07(23.33 \%)$ & $0.001^{6}$ \\
frequency & & & \\
\hline
\end{tabular}

Statistical test was performed by $Z$ test. $\mathbf{S}=$ Significant Increased frequency was more (23.33\%) with periinterventional antibiotic than subjects receiving continuous low dose antibiotic (6.67\%).

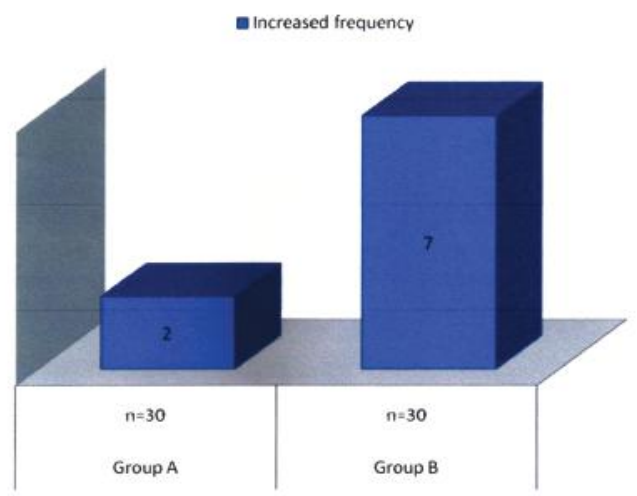

Fig.-8: Bar diagram showing increased frequency among the study subjects 
Table IX

GIT disturbance among the study subjects

\begin{tabular}{lccc}
\hline Outcome & $\begin{array}{c}\text { Group A } \\
n=30\end{array}$ & $\begin{array}{c}\text { Group B } \\
n=30\end{array}$ & $\begin{array}{c}\text { Statistical } \\
\text { test }\end{array}$ \\
\hline GIT disturbance & $05(16.67 \%)$ & $06(20.00 \%)$ & $0.328^{\mathrm{Nb}}$ \\
\hline
\end{tabular}

Statistical test was performed by $Z$ test. NS=Not Significant

GIT disturbance was observed in $16.67 \%$ cases receiving continuous low dose antibiotic and $20 \%$ in subjects with peri-interventional antibiotic.

\section{GIT disturbance,\%}

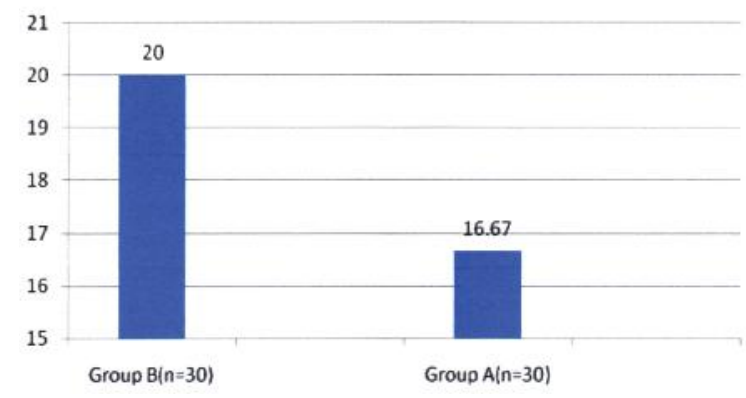

Fig.-9: Bar diagram showing proportion of GIT disturbance among the study subjects

Table X: Skin rash among the study subjects

\begin{tabular}{lccc}
\hline Outcome & Group A & Group B & Statistical \\
& $n=30$ & $n=30$ & test \\
\hline Skin rash & $07(23.33 \%)$ & $02(06.67 \%)$ & $0.001^{\mathrm{s}}$ \\
\hline
\end{tabular}

Statistical test was performed by $Z$ test.

$\mathrm{S}=$ Significant

Skin rash was significantly more in $23.33 \%$ subjects receiving continuous low dose antibiotic than $6.67 \%$ in subjects with peri-interventional antibiotic

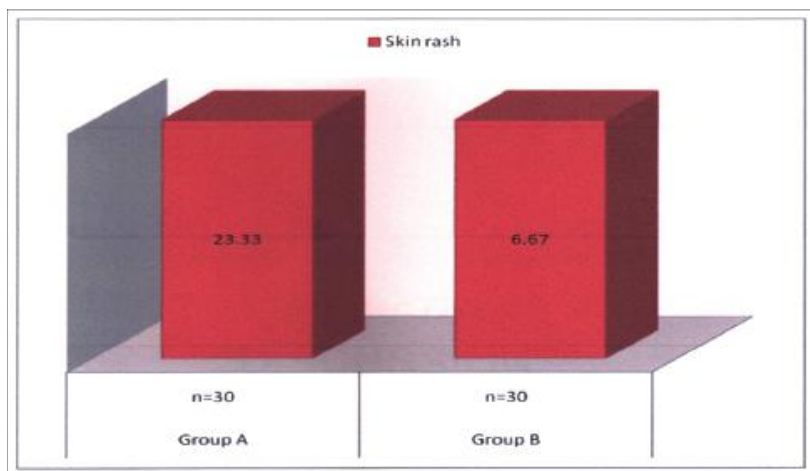

Fig.-9: Bar diagram showing proportion of Skin rash among the study subjects

\section{Illustration : Double J stent(own series)}

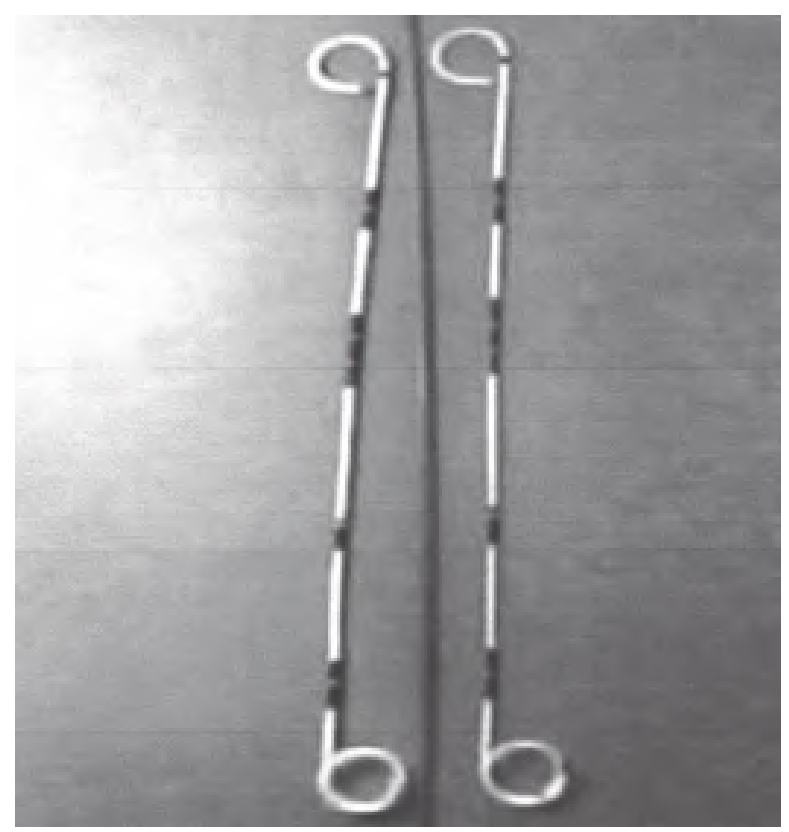

Illustration: Double J stent, endoscopic view (own series)

In some instances, one end of the stent has a thread attached to it that extends through the bladder and urethra to the outside of the body; this aids in stent removal. The stent material must be flexible, durable, non-reactive, and radiopaque (visible on an $\mathrm{x}$ ray). (Ramsay et al, 1985)

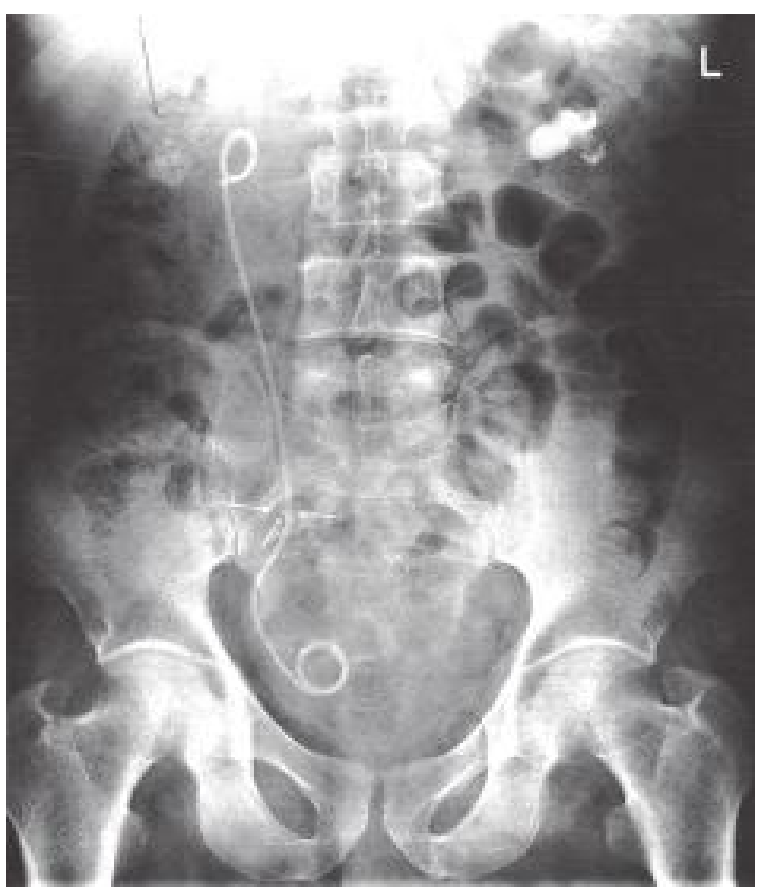

Illustration: $\mathrm{X}$ ray KUB region showing DJ stent in situ on right side(own series) 
Lennon et al, 1997 observed that if stent was given general anesthesia this ensures the physician that the patient will remain relaxed and will not move during the procedure. A cystoscope (a thin, telescope-like instrument) is inserted into the urethra to the bladder, and the opening to the ureter to be stented is identified. In some instances, a guide wire is inserted into the ureter under the aid of a fluoroscope (an imaging device that uses $\mathrm{x}$ rays to visualize structures on a fluorescent screen).

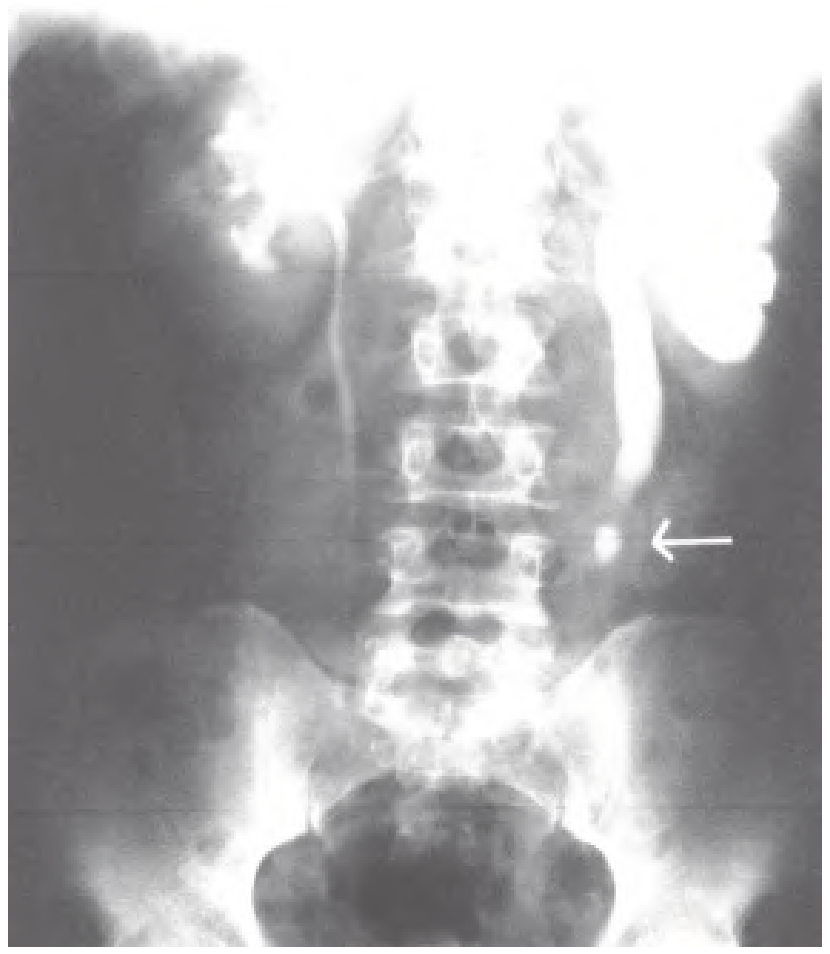

Illustration: IVU showing It ureteric stone with hydronephrosis and hydroureter.(own series).

\section{Discussion:}

Ureteral stents are one of the most common devices used by urologists. Ureteral stents are used to relieve ureteral obstruction, promote ureteral healing following surgery, and to assist with ureteral identification during pelvic surgery. Ureteral stent placement is associated with some degree of morbidity in the majority of patients that ranges from generalized urinary discomfort to urinary tract infection or obstruction. Much of the morbidity is related to the biocompatibility of the materials used to fashion the stent and, to some extent, their design; unfortunately, the ideal stent has yet to be discovered. For urinary tract infection rate the concept of a peri-interventional antibiotic prophylaxis during DJ stent implantation is known to be better antibiotic coverage and is therefore recommended by the European Association of Urology. However, there is a lack of evidence concerning the exact antibiotic strategy for the entire stent-indwelling time. In clinical routine, it is an applied practice among urologists to continue antibiotic treatment in a low-dose fashion, even after previous uncomplicated implantations. The intention is to lower the rates of UTIs and to achieve a positive effect on stent-related symptoms. This practice is supported by controversial recommendations from sparse publications. However, there exists neither evidence for the benefit, nor for the potential disadvantages of such empiric prevention. Moreover, increasing rates of bacterial drug resistances, growing overall healthcare costs and drug side-effects require a critical antibiotic prescription policy. This current study was carried out to evaluate the antibiotic treatment regime in patient with indwelling DJ stenting, the benefits and disadvantages of a peri-interventional antibiotic prophylaxis compared with those of a continuous low-dose antibiotic treatment by enrolling a total number of 60 subjects in the department of Urology, Dhaka Medical College, Dhaka. Among 60 subjects 30 subjects were Group A comprised of subjects treated with continuous low dose antibiotic and Group B with 30 subjects treated with peri-interventional antibiotic. The frndings of the study are discussed on basis of related previous studies concerning the objective of the study. In current study, the age ranged from 31-60 years and the maximum number was found in 41 to 50 years age group where majority were male in both groups. It was seen that, mean BMI was 23.74 $( \pm 3.52) \mathrm{kg} / \mathrm{m}^{2}$ in group A and $23.11( \pm 3.96) \mathrm{kg} / \mathrm{m}^{2}$ in group B. No significant difference was seen between two groups. Proportion of UTI was statistically more $(26.67 \%)$ among those subjects receiving periinterventional antibiotic than continuous low dose antibiotic supplementary $(10 \%)$. Dysuria was statistically less (10\%) among subjects receiving continuous low dose antibiotic supplementary than those with peri-interventional antibiotic (36.67\%). Proportion of Haematuria was less $(10 \%)$ in subjects receiving continuous low dose antibiotic supplementary than those with peri-interventional antibiotic (16.67\%). Increased frequency was more (23.33\%) with periinterventional antibiotic than subjects receiving continuous low dose antibiotic (6.67\%). GIT disturbance was observed in $16.67 \%$ cases receiving continuous low dose antibiotic and $20 \%$ in subjects with periinterventional antibiotic. Skin rash was significantly 
more in $23.33 \%$ subjects receiving continuous low dose antibiotic than $6.67 \%$ in subjects with peri-interventional antibiotic.

The routine and widespread use of broad-spectrum antibiotics has been responsible in part for the emergence of more virulent antibiotic-resistant bacteria in recent years ${ }^{(8)}$, and the doubling of methicillinresistant Staphylococcus aureus (MRSA) infection rates in intensive care units over the past 10 years[12]. Not surprisingly, there is a direct MRSA infection rate with the prophylactic use of third-generation cephalosporins. Likewise, the percentage of enterococci resistant to vancomycin has increased from $0.5 \%$ in 1989 to $25.9 \%$ in $1999[9,12]$ observed that Double $\mathrm{J}$ stent placement due to an obstructed ureter reflected one of the urologists' daily activities. Unfortunately, stent related symptoms could seriously impact daily activities/quality of life and also stentrelated infections could occur. 7 , conducted a study where 95 patients were randomised to either receive peri-interventional antibiotic prophylaxis during stent insertion only (group A, 44 patients) or to additionally receive a continuous low-dose antibiotic treatment until stent removal (group B, 51). It was seen that Neither the overall UTI rates (group A: $9 \%$ vs group B: $10 \%$ ), nor the rates of febrile UTIs (group A: $7 \%$ vs group B: $6 \%$ ) were different between the groups.

Similarly, SRS rates did not differ (group A: $98 \%$ vs group B: $96 \%$ ). Antibiotic side-effect symptoms were to be increased in patients treated with low-dose antibiotics. They concluded that continuous antibiotic low-dose treatment during the entire stent-indwelling time did not reduce the quantity or severity of UTIs and had no effect on SRSs either compared with a periinterventional antibiotic prophylaxis only. $[5,13]$ enrolled 95 patients in a randomized trial. Everyone received amoxicillin/clavulanic acid at anesthesia induction (1.2 $\mathrm{g} I V)$, and half the patients continued to receive it at a lower dose (625 mg daily) until stent removal and found there was no difference in rates of urinary tract infection (DTI) between the peri-interventional and continuous antibiotic groups ( $9 \%$ vs $10 \%)$. This was also the case for rates of febrile UTIs ( $7 \%$ vs $6 \%$ ), and stent-related symptoms ( $98 \%$ vs $96 \%)$. However, skin symptoms were seen in $14 \%$ of the continuous group compared to none of the other patients. Gastrointestinal symptoms were also significantly more common with longer-term treatment. They concluded that in contrast to the periinterventional approach, continuous antibiotic low-dose treatment implied undesirable disadvantages such as increased drug side effects and higher rates of resistant bacterial strains.

\section{Summary:}

This present study was carried out to evaluate the antibiotic treatment regime in patient with indwelling DJ stenting, the benefits and disadvantages of a periinterventional antibiotic prophylaxis compared with those of a continuous low-dose antibiotic treatment among total number of 60 subjects in the department of Urology, Dhaka Medical College, Dhaka. Among 60 subjects 30 subjects were Group A comprised of subjects treated with continuous low dose antibiotic and Group B with 30 subjects treated with peri-interventional antibiotic. Outcome of these two treatment techniques were studied. Proportion of UTI was statistically more $(26.67 \%)$ among those subjects receiving periinterventional antibiotic than continuous low dose antibiotic supplementary (10\%).

\section{Conclusion:}

From the present study it could be concluded that in case of with indwelling DJ stenting, subjects with continuous low dose antibiotic regimen had significantly less proportion of UTI, dysuria and frequency of micturition than those with peri-interventional antibiotic. But continuous low antibiotic regimen had more side effect like skin rash than peri-interventional antibiotic regimen. However, haematuria and GIT disturbance was not different between two groups. So, if haematuria, skin rash and GIT disturbance is carefully managed then continuous low dose antibiotic regimen may be better treatment option than peri-interventional regimen for with indwelling $D J$ stenting in different cases.

\section{Limitation of the study:}

1. Relatively shorter study period and only one centre enrollment (Dhaka Medical College Hospital).

2. Relative small number of sample size in getting accurate outcome.

3. The study was analyzed among the patients who attended Dhaka Medical College Hospital only and therefore the entire situation of the patients with indwelling DJ stenting in the country have not provided.

\section{Recommendations:}

- $\quad$ Further study with a larger sample size involving multiple centers.

- Application of continuous low dose antibiotic regimen for indwelling DJ stenting. 


\section{References}

1. Akay, A.F., Aflay, U., Gedik, A., Sahin, H., Bircan, M.K. 2007. Risk factors for lower urinary tract infection and bacterial stent colonization in patients with a double $\mathrm{J}$ ureterlal stent. Int Urol Nephrorl .vol.39, pp. 95-8.

2. Damiano, R., Autorino, R., De SIO, M.,Cantiello, F., Quarto,G.,Perdona,s. et al. 2005. Does the size of ureteral stent impact urinary symptoms and quality of life? A prospective randomized study. Eur Urol .vol. 48,pp. 673-8.

3. Irani, J., Siquier, J.,Pires, C. ,Lefebvre, O., Ore,D., Aubert, J .1999. Symptom characteristics and the development of tolerarce with time in patients with indwelling double-pigtail ureteric stents. BJU Int. vol.84,pp. 276-9.

4. Joshi, HB., Stainthorpe, A.,Mac Donagh, RP.,Keeley ,FX.Jr., Timoney, AG., Barry, MJ. 2003. Indwelling ureteral stents:evalution of symptoms, quality of life and utility. Urol.vol. 169,pp. 1065-9.

5. Kehinde, EO., Rotimi, VO., AL-Hunayan, A., Abdul-Halim ,H., Boland, .F,AL-Awadi .KA. 2004. Bacteriology of urinary tract infection associated with indwelling $\mathrm{J}$ ureteral stents.J ENDOUROL .vol. 18,pp.891-6.

6. Klis, R., Korczak-Kozakiewicz, E., Denys, A., Sosnowski, M.,Rozanski, W,.Rrlation. 2009. between urinary tract infection and self-retaining Double -J catheter colonization. JEndouro/. vol.23,pp.1015-9

7. Moltzahn, F., Haeni, K., Birkhauser, FD., Roth, B., Thalmann, GN., Zehnder, P. 2013.Periinterventional antibiotic prophylaxis only vs continuous low-dose antibiotic treatment in patients with JJ stents: a prospective randomised trial analysing the effect on urinary tract infections and stent-related symptoms. BJU /nf.vol. 111, no.2, pp. .289-95.

8. Mulvey, M R., Simor, A E. 2009. Antimicrobial resistance in hospitals: how concerned should we be? CMAJ. Vol.180,no. 4,pp.408-415.

Negrete-Pulido O, Gutierrez-Aceves J. 2009. Management of infectious complications in percutaneous nephrolithotomy. J Endourol. Vol.23,no.10,pp.1757-1762.

9. Nicastri, E., Leone ,S., Petrosillo ,N., Pisanelli,C.,Magrini,P.,Cerequetani,F., et al. 2008. Decrease of methicillin resistant Staphylococcus aureus prevalence after introduction of a surgical antibiotic prophylaxis protocol in an Italian hospital. New Microbiol. Vol. 31,pp .519-525.

10. Ramaswamy, K., Shah, O. 2012. Antibiotic Prophylaxis After Uncomplicated Ureteroscopic Stone Treatment: Is There a Difference? Journal of Endourology. Vol.26,no.2,pp. 122

11. Ramsay ,JW., Payne, SR., Gosling, PT., Whitfield, HN., Wickham, JE., Levison ,DA. 1985.The effects of double $\mathrm{J}$ stenting on unobstructed ureters. An experimental and clinical study. $\mathrm{Br} J$ Urol. Vol. 57,no.6,pp.630.

12. Reddy, P., Chadaga ,S., Noskin, G A .2009. Antibiotic considerations in the treatment of multidrug-resistant (MDR) pathogens: a casebased review. J Hosp Med. Vol. 4,no.6,pp.8-15.

13. Saltzman, B. 1998. Ureteral stents. Indications, variations, and complications. Urol din North Am. liol 15,pp. 481-91. 